Document downloaded from:

http://hdl.handle.net/10251/63802

This paper must be cited as:

Paredes Arquiola, J.; Andreu Álvarez, J.; Solera Solera, A. (2010). A decision support system for water quality issues in the Manzanares River (Madrid, Spain). Science of the Total Environment. 408:2576-2589. doi:10.1016/j.scitotenv.2010.02.037.

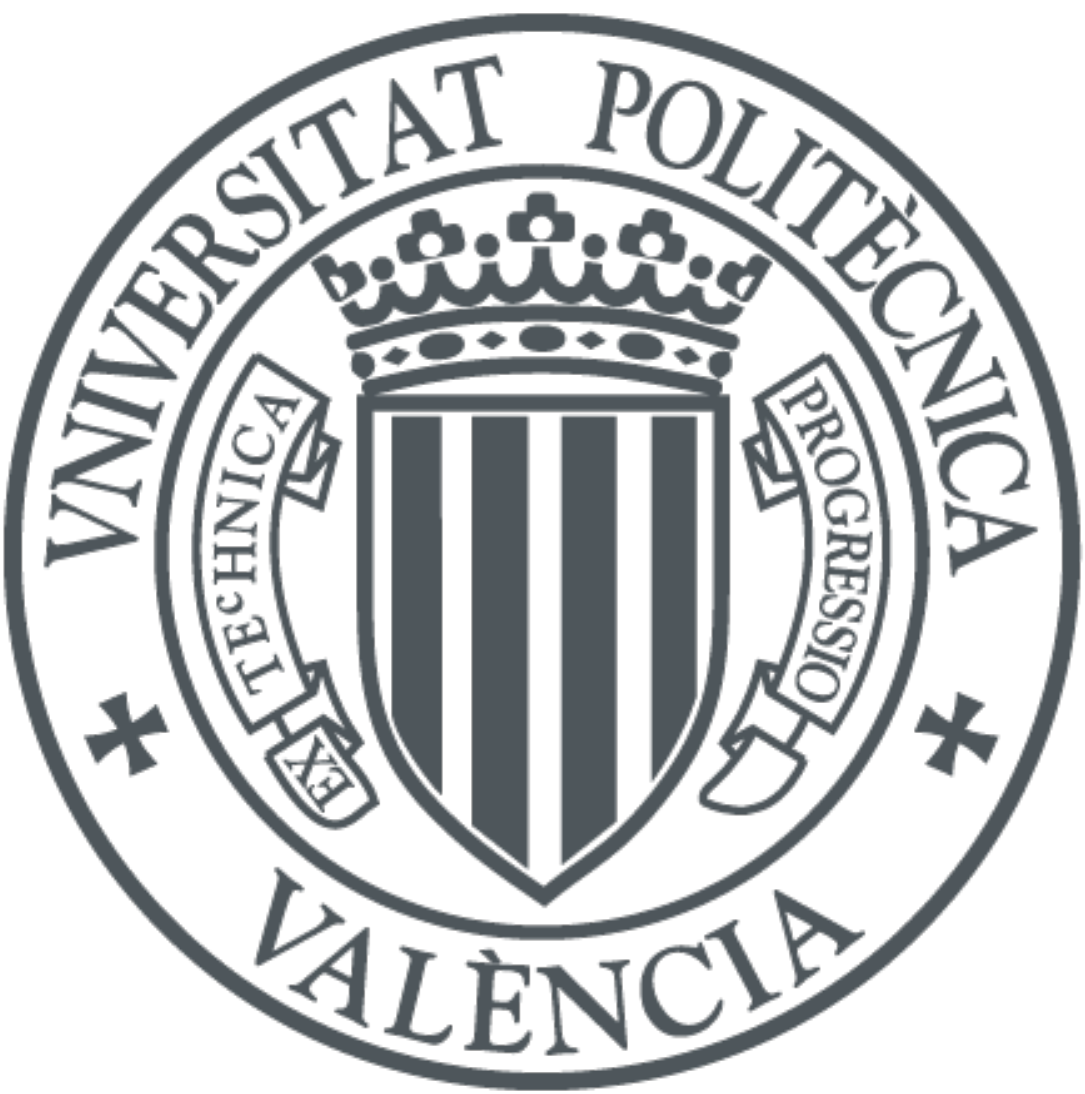

The final publication is available at

http://dx.doi.org/10.1016/j.scitotenv.2010.02.037

Copyright Elsevier

Additional Information 


\title{
DECISION SUPPORT SYSTEM FOR WATER QUALITY ISSUES IN MANZANARES RIVER (MADRID, SPAIN)
}

\author{
Javier Paredes, Joaquín Andreu, and Abel Solera. \\ Water and Environmental Engineering Institute. \\ Technical University of Valencia. Spain. \\ (jparedea@hma.upv.es)
}

\begin{abstract}
The Manzanares River, located in Madrid (Spain), is a main water supplier of a highly populated region and the receptor of the wastewater from the same area. Major pressure consists on 8 Waste Water Treatment Plants (WWTPs) that represent $90 \%$ of the flow in the medium and low part of the river. Although situation has slightly improved in the last two years, water quality is highly polluted, making impossible any aquatic life. Water quality modeling is the most used approach for assessing the effect of treatment improvements in water bodies. In this work, GESCAL module of Aquatool Decision Support System Shell is used for simulating water quality in Manzanares River. GESCAL is appropriate for modeling whole water resources systems, including reservoirs and rivers. A model of conductivity, phosphorous, carbonaceous organic matter, dissolved oxygen, organic nitrogen, ammonia, and nitrates has been built. Due to many modifications in the period from October 2006 to September 2008, this period was selected for calibration and a previous, and longer, from October 2000 to September 2006 was used for validation. Furthermore, a daily model was used to analyze the robustness of the model. Once the model has been validated, different scenarios are considered and simulated. First, different combinations of nutrient elimination among the different WWTPs have been tried. It is concluded that investments have to focus on three of the proposed WWTPs. Moreover, these treatments will not be enough to maintain fish habitat conditions at all times. Then, additional measures, as increment of the flow in the river, or oxygen injection, have been simulated. Increment flows in Manazanares is an efficient measure, but implies an increment of risk of scarcity situation in Madrid water supply system.
\end{abstract}

\section{Introduction}

Increment of water use has as consequence reduction of river flows, less dilution and minor self-depuration capacity. An extreme case of this situation is Manzanares River, located (figure 1) in Madrid (Spain). It is, perhaps, the most polluted river in Spain, at least regarding to the rate between natural flow and discharges. Manzanares River has its origin in Guadarrama Mountains, where the water is crystalline and very suitable for human consumption. For this reason, it is part of a system that supplies Madrid Metropolitan Area from three rivers, namely Manzanares, Guadarrama, and Jarama. These rivers are part of the Tagus basin, one of the main rivers of the Iberian Peninsula, flowing from Spain to Portugal. As the headwaters are been used and regulated for supply purposes, the medium and low part of these three rivers are used as natural reception water bodies of the wastewater of Madrid. 
The component catchment area of Manzanares is $4802 \mathrm{~km}^{2}$. The area of the study starts downstream El Pardo reservoir, the last headwater reservoir, and finishes just in the confluence with Jarama River. The length of the river reach between these two points is $46.5 \mathrm{~km}$. The Manzanares River flows from Northwest to Southeast, passing through Madrid, a heavily urbanized area. Major environmental pressures are the effluents of WWTPs for a population of 6 million of inhabitants.

The Manzanares River is characterized by very regular flows and discharges. The water released from El Pardo reservoir is constantly equal to $1 \mathrm{~m}^{3} / \mathrm{s}$. Only during flood events the flow is greater. Discharge flow from the eight WWTPs is about $10 \mathrm{~m}^{3} / \mathrm{s}$. This means that more than $90 \%$ of the water flowing in the Manzanares River downstream of Madrid comes from treated wastewater. Currently, the WWTPs also collect urban runoff.

The river reach studied can be classified in three parts. First part goes from the El Pardo reservoir to the first discharge (Viveros WWTP). In this area the river has a natural morphology and the flows are constants and low. Viveros WWTP discharge is about the same quantity as the flow of the river in that point. Downstream, the river is transformed in a channelized urban river passing through the centre of Madrid City. Once the river escapes from this highly urbanized stretch, it flows to an area of suburbs with more natural riverine conditions. In this third part, the river receives point loads of La China, La Gavia, Butarque, Sur and Sur Oriental WWTPs. Moreover, in this part merges with Culebro river, an affluent that collects 2 more point discharges.

In total, there are 8 main WWTPs in the Manzanares River. Prior to 2006, municipal authorities managed the facilities. From that date, Canal Isabel II (CYII), the same company that manages water supply to Madrid, is in charge of all the WWTPs. For this reason, many changes have been produced in the plant discharges in the last two years. Table 1 collects main data about flow and effluent concentration of the plants. All of them have secondary treatment and are improving the treatments. As it can be seen, La China, Butarque, and Sur are the main focus of pollution under flow criteria. These three facilities together sum more than $7.35 \mathrm{~m}^{3} / \mathrm{s}$. Under effluent concentration criteria, the more downstream located plants are the more pollutant. Madrid MA is more industrialized in the SE part and more residential in the NW. For example, La 
China effluent has an average conductivity effluent of $566 \mu \mathrm{s} / \mathrm{cm}$, while Sur Oriental effluent has about $1522 \mu \mathrm{s} / \mathrm{cm}$.

During the year 2006 the treatments improved and so did the effluents concentration. The constituent that improved more was phosphorous due to the fact that all the WWTPs reduced effluent concentration to less than $1 \mathrm{mg} / \mathrm{l}$. Presently, there are two reasons why water quality in Manzanares is a concern. First, because municipal authorities are building riverine esplanades in order to transform the shore of the river into a municipal park. This will lead people to access the river banks, and will increment their concern about water quality. And second, because Water Framework Directive (EC, 2000) establishes that member countries must apply sufficient measures to water bodies in order to achieve good ecological status by the year 2015 . For strongly impaired water bodies, it is mandatory to assess the maximum possible ecological status and the measures to achieve it, taking into account the cost-effectiveness of the measures.

This paper presents a water quality model for the medium and low part of the Manzanares River. Models are able to provide predictions of the behavior of the system in possible future conditions. The purpose of the model is to assess the maximum potential ecological status and to optimize future investments in water treatments. First, we examine the present situation of water quality in the river, serving as the basis for the investigation of the future treatment impacts. Second, a brief explanation about the water quality model used is given. Results of calibration and validation are presented in the third part of the paper. The analysis of the results of different proposed simulations show the best policy for investing in treatment facilities in the upcoming future, and the effect of other possible additional measures.

\section{Present water quality situation.}

As mentioned above, headwaters of Manzanares River are of exceptional water quality. In this study, we examine the conventional constituents, not taking into account toxics, in the medium and low part of the river. For the analysis, and later for calibration of the model, we use data from the monitoring program of the Tagus Basin Agency (TBA) that collects samples each month at several points in the river. In order to 
understand the main elements of the system, figure 2 displays the location of the discharges and the measurement points.

In the first part of the river reach modelled, water has a good quality; perhaps initially it is influenced by the hypolimnion conditions of the El Pardo Reservoir, but in a few kilometres it achieves its natural condition. Water quality stations of "El Pardo" and "Parque Sindical" characterises the situation in this initial part of the river. Conductivity is low, about $400 \mu \mathrm{s} / \mathrm{cm}$, due to the granitic geology of the basin. The organic matter, carbonaceous and nitrogen, are very low and dissolved oxygen is approximately near $100 \%$ saturation. Flows released from El Pardo Reservoir are constant and approximately equal to $1 \mathrm{~m}^{3} / \mathrm{s}$, except during flood events, where flows can increase up to more than $30 \mathrm{~m}^{3} / \mathrm{s}$.

Downstream "Parque Sindical" quality station, the Viveros WWTP discharges $1 \mathrm{~m}^{3} / \mathrm{s}$, and this is the initial point of the second part of the river reach modelled, where it is channelized and crosses Madrid city. The length of this second part is approximately $10 \mathrm{~km}$, and there are no WWTP discharges in this area. Although the Viveros WWTP discharge is the in the same order of the river flow, water quality is not impacted as it would be expected. This is due to the facts that Viveros WWTP has an excellent treatment and that the wastewater has no industrial component. San Fermin water quality station, located where the river leaves downtown Madrid, shows levels of conductivity of $490 \mu \mathrm{s} / \mathrm{cm}$. Dissolved oxygen concentrations has an average of $8.34 \mathrm{gm} / \mathrm{l}$ and minimum values of $4.5 \mathrm{mg} / \mathrm{l}$. However, ammonia concentration is high and disperse, being a constant problem in all the river downstream this point.

Downstream, the third part of the river reach modelled passes trough industrial and residential suburbs, and is characterized by many discharges, mainly, five big WWTPs and a polluted tributary. Nevertheless, riverine conditions are good. The amount of total discharge by all these plants is about $9 \mathrm{~m}^{3} / \mathrm{s}$, and some of them have a high industrial component. The critical point is located in "Rivas Vaciamadrid", a suburb of Madrid. A water quality station is located at this point. Ammonia concentrations range is $20-50 \mathrm{mgNH} 4 / \mathrm{l}$, anoxia is frequent, conductivity is about $900 \mu \mathrm{s} / \mathrm{cm}$, and average concentration of BOD 5 is $25 \mathrm{mg} / \mathrm{l}$. In the third part of the river reach modelled, concentrations of the constituents are even greater than a common outflow of a WWTP. For example, water temperature has minimal daily oscillation, and in winter the 
minimum daily water temperature is $15^{\circ}$ when air temperature is under zero. Even in this situation, the river has some self depuration, as it can be tested with the model performance. Nevertheless, in the last two years, a slight improvement has been observed, the number of anoxia situations is less, and phosphorous concentrations have decreased dramatically. But, ammonia and nitrogen constituents are still very high, and $\mathrm{BOD}_{5}$ is not low enough.

\section{Tools and methods.}

Currently, there exist different water quality models for rivers and streams, and possibly, QUAL2 family (Brown and Barnell, 1987; Chapra and Pelletier, 2003) models are the most used in the world, with a long history of application (Somlyody et al., 1998; Park and Lee, 1996). Other traditional models, such as WASP (Ambrose et al., 1987), or CE-QUAL-RIV1 (Environmental Laboratory, 1995), have been used depending on diverse factors as availability of data, nature of the problem, or other reasons, as basic as the knowledge of the user.

In the present case, GESCAL program is used. It is a tool that allows the development of water quality models for water resources systems including rivers and reservoirs. The water resources system is represented by a network including different elements as: inflows, arcs, nodes, reservoirs, demands, aquifers, hydroelectric power plants, artificial recharge elements, and pumping facilities. A complete and detailed description of the model can be found in (Paredes et al, 2004). GESCAL is coupled to a water resources management simulation model, SIMGES (Andreu et al., 1992). Therefore, complex water quality and management can be dealt with in a unique environment. SIMGES is a traditional and very much used model in Spain for water resources management. Another advantage of using GESCAL is that, together with SIMGES and other modules, it is a part of AQUATOOL (Andreu et al. 1996) a Decision Support System Shell with a very powerful interface in order to create, edit and manage water resources models. The use of AQUATOOL makes the task of creating a water quality model very easy for any engineer or a technician. 
The program gives to the user the possibility to model temperature, arbitrary constituents, CBOD, dissolved oxygen, organic nitrogen, ammonia, nitrate, organic phosphorous, phosphates and Chlorophyll-a. For the Manzanares River case, a model using only arcs, nodes and inflows was developed. Any arc is representing a homogeneous segment of river and the model considered is mechanicistic, one dimensional, stationary, advective and dispersive. GESCAL allows modelling multiple situations of flows and loads. Obviously, as it is a stationary model each situation is treated independently. The GESCAL model was employed to determine the evolution of conductivity, CBOD, dissolved oxygen, ammonia, organic nitrogen, nitrates and phosphorous in the Manzanares River. Conductivity was considered as a conservative pollutant and phosphorous as an arbitrary one. A sedimentation velocity was calibrated for phosphorous, representing the particulate part that sediment with solids. This is because there is a lack of data among the chlorophyll-a set, and there is no evidence about eutrophication problems in this stretch of the river. Figure 3 shows the kinetics and variables considered in this study. Nitrogen is modelled as organic, ammonia, and nitrate. Processes considered included sedimentation and degradation of CBOD, ammonification and sedimentacion of organic nitrogen, nitrification of ammonia, denitrification of nitrate, reaireation and sediment oxygen demand, and sedimentation (or/and degradation) of phosphorous.

\section{Model Application.}

The stretch of the river among el Pardo and Jarama River was divided in 14 reaches, represented by arcs in GESCAL. Figure 4 displays the network of the model. These reaches were selected on the basis of, either significant change in hydraulic characteristics, or in water quality. Intermediate nodes are used to locate inflows from discharges, or because they are the location of a sampled site. The computational length discretization elements were set to $50 \mathrm{~m}$.

The flow gauging stations at Manzanares River are located in the boundaries of the system: downstream of El Pardo reservoir, and upstream of the junction with Jarama River. A mass balance for flows was performed with river measured flows and inflows from discharges. Data for discharges previous to 2006 
were mistaken, so they were obtained by factoring in proportion to the difference between flows measures in both stations. For the last period, the balance of flows presents an average error of $0.8 \mathrm{~m}^{3} / \mathrm{s}$. A detraction of flows due to evaporation and irrigation of little crops in summer time have been considered; this number is about $1.3 \mathrm{~m}^{3} / \mathrm{s}$ in summer time.

Due to stationary conditions of the river, for calibration purposes we use water quality data from the monthly routinely surveys of the Tagus Basin Agency. There are five locations (Pardo, Parque sindical, San Fermin, Villaverde, and Rivas Vaciamadrid) where technicians have measured each month from October 2000 until present all constituents considered in this study. The main uncertainty of using these data for modelling purposes is the travel time in the river. However, special conditions of this river, as steady flows and discharges, allow to consider the measured concentration as representative of each month.

Data of discharges come from CYII, they provide flow and concentration discharges. There are daily records of flows and concentration discharges from 2006. Before 2006 it is available monthly data of flow WWTP discharge. Regarding concentrations of the discharges there are a mean monthly data from every WWTP.

Finally data of flows in the river are obtained from two gauged stations located just downstream of the reservoir and upstream confluence with Jarama. Gauged flows are continuously but it was used a mean monthly flow for the stationary model.

Input time series of lows and concentrations were prepared for GESCAL to the natural inflows and the WWTP point discharges. The hydraulic coefficients required by the model were determined by regression of the hydraulics parameters. The longitudinal dispersion coefficient was evaluated based on the physical analysis of each reach.

\section{Calibration and Validation.}

Application of a model generally includes calibration and confirmation (Chapra, 2003). Calibration of the parameters of the model was performed by trial and error, trying to maintain similar parameter values in reaches of the same parts described above. A reasonable fit between the measurements and the simulations results was obtained. Model results are highly coherent with measured data in almost all the observed 
locations. Last point has more uncertainty due to the fact that it is affected by several focus of pollution. Due to improvements in the WWTP in the last two years, we decide to take only this period (October 2006 September 2008) for calibration. All the calibrated parameters are inside the ranges established in the literature (Bowie et al. 1985; Campbell, 1985). Table 2 shows values of tuned parameters obtained after calibration. Concentration profiles of measured, calibrated and validated results can be seen in figure 5 (a-e). Re-aeration coefficient was calibrated because Covar method (Covar, 1976) was not producing good results. CBOD degradation constant is low as consequence of the secondary treatment of WWTP. Finally, although in the last part of the river reach modelled the velocity of nitrification is high, measures of the concentrations show that it is not high as it could be. Nitrification rate has important influence in dissolved oxygen and nitrate concentrations. A compromised was decided between nitrification rate and organic nitrogen parameters given their influence in the four variables (dissolved oxygen, organic nitrogen, ammonia, and nitrates). Perhaps nitrate concentrations are overestimated in the model, but it was a sacrifice in order to improve the match of ammonia and dissolved oxygen. Main factors altering DO levels are nitrification and degradation of CBOD. No information on sediment of the Manzanares River was available. Thus, sediment oxygen demand was considered as another parameter of the model, but sensitivity analysis proved it was not a relevant parameter.

Even if a model successfully simulates an independent data set in the verification phase, all that can be concluded at the best is that our testing has not proved the model wrong (Chapra, 1997; Oreskes et al. 1994). Traditional approach of calibration - validation implies the use of first temporal data for calibration and more modern data set for validation. In our case, given the improvement of the operation of all WWTP as a consequence of the change in the management and new treatments, it is not advisable to use the last part of the temporal series for validating the model. Therefore, the last and short period (oct 2006- sep 2008) was used for calibration, and the longer and previous period (oct 2000- sep 2006) was used for validation. This approach can be called "backwards validation" to differentiate it from the traditional approach. Parameters are not changed, even knowing that in this period degradation was higher. However as figure 5 (a-e) displays, the validation was good. 
Finally, in order to evaluate the robustness of the model, a daily model was elaborated and then data from a continuous station located in Rivas Vaciamadrid were used to validate the model. In the last period daily data of releases from reservoir, outflows of WWTP and water quality are available. The model was fed with this data, and assuming that concentrations of discharges are uniform within each month. Available data from the continuous station are conductivity, dissolved oxygen and ammonia. It has to be noticed that the model considers each day independent of the others and this assumption can be made because the travel time of the study area is greater than one day. This exercise helps to validate the model in a non traditional way; we call this methodology "validation by changing time scale". With this approach uncertainty due to the time scale can be estimated. Figure 6 (a-c) plots the results that have been obtained. As it can be seen, three constituents match reasonably well. Conductivity results are more flat than measured as a consequence of the lack of daily concentration in discharges. Dissolved oxygen has different periods of behaviour, sometimes underestimating the measured values. Finally, ammonia has the best fit of the 3 constituents, at least for the period of available data.

\section{Analysis of scenarios}

The established model was applied to analyze the effect of possible measures to improve water quality in the river. First, the impact of nutrient removals treatments was evaluated. Two scenarios were considered: one (named 3G) in which the treatment is implanted only in the three greater WWTPs: La China, Butarque and Sur; then, the response of the river in case all the plants reduce nitrogen and phosphorous (named ALL) is evaluated. If nitrogen removal is applied then discharge concentrations are changed to $0.1 \mathrm{mgN} / 1$ for Norg, 1 $\mathrm{mgNH} 4 / 1$ for ammonia, and $40 \mathrm{mgNO} 3 / \mathrm{l}$ for nitrate. If phosphorous removal is considered the concentrations of the discharges are changed to $1 \mathrm{mg} / \mathrm{l}$ for phosphorous. The objective is to achieve a reduction in nutrients, but also to obtain enough dissolved oxygen concentration in the river to accomplish European standard for fish habitat criteria (EC, 2006) (4 mg/l). 
Figure 7 (a-d) represents simulation results for the different constituents in the river. As is can be seen, reduction of nutrients in scenario $3 \mathrm{G}$ implies that ammonia in the river could change to values lower than 5 mgNH4/l. Even though the treatment would decrease dramatically ammonium concentrations, it cannot be said that the river will have a good status. For example, European standard recommend $1 \mathrm{mg} / 1$ for fish protection. Dissolved oxygen also improves with respect to the present situation. And, in most of the months, simulated concentrations are greater than the objective in critical point Rivas Vaciamadrid (figure 7 a-d). However, in some situations they are lower or near to the goal. It has to be pointed out that no safety factor was considered. Finally, it is remarkable that, although total nitrogen is lower in $3 \mathrm{G}$ scenario, the nitrate concentrations will be significantly increased passing from present $10-20 \mathrm{mgNO} / \mathrm{l}$ concentrations greater than $40 \mathrm{mgNO} 3 / \mathrm{l}$.

In the same figure 7 (a-d) it is possible to compare 3G and ALL scenarios. Results show that it is not efficient to invest in reduction nutrients in the other 5 plants. Due to the fact that the discharge of the $3 \mathrm{G}$ plants is about 75 percentage of the total wastewater, the effect of reducing nutrients in the other plants is not very significant. Moreover, it does not imply enough improvement in the dissolved oxygen concentrations. Although it could be obvious, it is important to remark that efforts have to be focused in the maximum improvement of the water quality of the China, Butarque, and Sur WWTPs due to their effect in the river.

The same result is obtained for phosphorous. As it can be seen, the present level of phosphorous in the river could not be improved significantly with phosphorous treatment in the other plants.

Assuming as a new base situation the $3 \mathrm{G}$ scenario, it is necessary to improve water quality in the river, overall concerning dissolved oxygen concentrations. Therefore, two measures have been tested. First, we test how much dissolved oxygen would be needed to be injected in the river in order to achieve the DO concentration goal. The dissolved oxygen was considered as a distributed inflow in the last two reaches. In total $0.5,1$ and $1.510^{3} \mathrm{Kg} / \mathrm{d}$ were tested as possible. Figure $7-\mathrm{d}$ displays results in oxygen concentration in Rivas Vaciamadrid. They show that with $110^{3} \mathrm{Kg} / \mathrm{d}$ the goal was obtained. This amount of oxygen does no 
need to be injected all the time, since the continuous sampling station could be used as a system alarm to decide when to use this measure. Designing of the facility is out of the scope of this study.

Finally, another explored possibility flow in the river augmentation. This implies extra releases from El Pardo reservoir. A set of flow values were simulated ranging from 1.5 to $3 \mathrm{~m}^{3} / \mathrm{s}$. Water quality from upstream reservoir is very good, so it would improve concentrations in the river diluting discharges. Figure 7-d shows different concentrations of dissolved oxygen in Rivas Vaciamadrid for the flows tested. It would be necessary an increment to $3 \mathrm{~m}^{3} / \mathrm{s}$ from El Pardo to assure the achievement of the DO goal. However, ammonia objective of $1 \mathrm{mg} / \mathrm{l}$ is not very likely to be obtained. Although this possibility could be very interesting because it means giving back natural flows to the river, the main problem is the reliability of water supply to Madrid City. The purpose of headwaters reservoirs of Manzanares, Jarama and Guadarrama is water supply for Madrid City. This system, also managed by CYII, has frequent scarcity situations forcing to import water from external basins. Even so, it is a possibility to be considered by the managers after assessing the risk of increment flows in Manzanares.

\section{Conclusions}

This paper analyzes the medium and low stretch of Manzanares River, that is highly polluted due to the low natural flow and to many urban discharges. Presently, water quality problems are related to low dissolved oxygen concentrations, high ammonia content in the water, and conductivity 3 or 4 times the natural concentration. Furthermore, the nutrients contribution from this area is the main part of nitrogen and phosphorous of the entire Tagus basin, with many eutrophication problems in the reservoirs.

In order to assess the maximum ecological status and to evaluate effectiveness of measures, a water quality model has been developed for the river Manzanares. The program used was GESCAL, a water quality model integrated in AQUATOOL DSS. Although GESCAL can be used for complete water resources system in this case only a river reach has been modeled. Constituents considered have been conductivity, phosphorous, dissolved oxygen, organic matter, and nitrogen in different forms. 
As a result of the study, it has been concluded that nutrients should be eliminated from the three biggest WWTP and that implementation of nutrients removal in the other plants is not justified. The optimum policy is to accumulate volume in China, Butarque and Sur WWTP and to improve their treatments as much as possible. However, even removing nitrogen, to achieve $4 \mathrm{mg} / \mathrm{l}$ of dissolved of oxygen in the river will not be possible all the time. Thus, it will be necessary to introduce additional measures to improve dissolved oxygen in the river. Among them, two possible solutions have been tested. The first measure is to increment natural flow in the river by releasing more water from El Pardo reservoir. This measure would improve water quality in terms of all constituents, but it is a risk for the reliability of Madrid city water supply. Even so, a detailed study of the impact of the water flow augmentation of Manzanares River should be done. Finally, another possibility is the increment of dissolved oxygen concentrations by means of diffusers located in the low part of the river. The model has allowed the assessment of the mass of oxygen necessary after the nutrients removal is done in the three biggest WWTPs, which is estimated in the order of $1 \mathrm{Tn} / \mathrm{d}$ of oxygen.

Improvement of water quality in Manzanzares River is a great challenge to face in order to accomplish WFD and also to allow the upcoming access of population of Madrid to the riverine area. Investments in waste water treatment have focus on Viveros, Butarque and Sur plants, since they have greater influence in the river. The model developed is a valuable tool in order to analyze water quality processes in the river and to test different measures for improving this issue.

\section{Acknowledgements}

The authors would like to thank the European Communities for financing the project "Water Resources System Planning, WARSYP", contract ENV4-CT97-0454 (DG XII Science, Research \& Development); the project "Water resources Management Under Drought Conditions, WAM-ME", contract ICA3.1999.00014 
(D XII Science, Research \& Development); and the project "SEDEMED - Sécheresse et Desertification dans les bassins méditerranées", ref. 2002-02-4.4-1084 (INTERREG III B-Mediterranée Occidentale).

Also, thanks are due to Ministerio de Educación y Cultura de España (Comisión Interministerial de Ciencia y Tecnología, CICYT) for financing of the project "SADIDMA"(CGL2005-07229/HI) contract, and the project “INTEGRAME” contract CGL2009-11798.

As well, gratitude is expressed to Confederación Hidrográfica del Tajo (Spanish Ministry of Environment) for data provided to develop this study.

\section{REFERENCES}

Andreu, J., Capilla, J., y Sanchís, E., AQUATOOL: A generalized decision support-system for waterresources planning and operational management, Journal of Hydrology, 1996, Vol. 177, pp. 269-291

Andreu, J., Capilla, J. y Ferrer, J., Modelo Simges de simulación de la gestión de esquemas de recursos hídricos, incluyendo utilización conjunta, España, Servicio de Publicaciones, UPV, 1992,. pp 230.

Ambrose, R.B., Wool, T.A., Connolly, J.P., Shanz, R.W., 1987. WASP5, a Hydrodynamic and Water Quality Model. EPA/600/3-87/039, U.S. Environmental Protection Agency, Athens, GA.

Bowie, G.L., Pagenhopf, J.R., Rupp, G.L., Johnson, K.M., Chan, W.H., Gherini, S.A., Mills, W.B., Porcella, D.B., Campbell, C.L., 1985. Rates, Constants and Kinetics Formulation in Surface Water Quality Modeling, second ed. EPA/600/3-85/040, U.S. Environmental Protection Agency, Athens, GA.

Brown, L., Barnwell, T.O., Jr., 1987. The Enhanced Stream Water Quality Models QUAL2E and QUAL2E-UNCAS: Documentation and User Manual. Report EPA/600/3-87/007. U.S. Environmental Protection Agency, Athens, GA.

Campbell, C.L., 1985. Rates, Constants and Kinetics Formulation in Surface Water Quality Modeling, second ed. EPA/600/3-85/040, U.S. Environmental Protection Agency, Athens, GA.

Chapra, S.C., 1997. Surface Water-Quality Modeling. Mc-Graw-Hill Inc., New York p. 844.

Chapra, S.C., 2003. Engineering water quality models and TMDLs. Journal of Water Resources Planning and Management 129 (4), 247-256.

Chapra , S.C., and Pelletier, G., 2003. QUAL2K: A modelling framework for simulating river and stream water quality. Documentation and user manual. Civil and Environmental Department, Tufts University, Medford, MA.

Covar, A. P. 1976. "Selecting the proper reaeration coefficient for use in water quality models." Presented at the U.S. EPA Conference on Environmental simulation and Modeling, April 19.22, Cincinnati, $\mathrm{OH}$. 
EC (2000) "Directive 2000/60/EC of the European Parliament and of the Council, of 23 October 2000, establishing a framework for Community action in the field of water policy". Official Journal of the European Commission, L 327/1,22.12.2000

EC(2006). "Directive 2006/44/EC of the European Parliament and of the Council, of 6 September 2006, on the quality of fresh waters needing protection or improvement in order to support fish life". Official Journal of the European Commission, L 264/20,25.9.2006.

Environmental Laboratory. 1995. CE-QUAL-RIV1: A dynamic, one-dimensional (longitudinal) water quality model for streams, user's manual, Instruction Report E-90, U.S. Army Engineers Waterways Esperiment Station, Vicksburg, Ms.

Park, S.S., Lee, Y.S., 1996. A multiconstituent moving segment model for the water quality predictions in steep and shallow streams. Ecological Modelling 89, 121-131.

Paredes, J., Solera A., and Andreu J., 2004. Modleo Gescal para la simulación de la calidad del agua en sistemas de recursos hídricos. Manual de usuario. Universidad Politécnica de Valencia. Valencia (Spain).

Somlyody, L., Henze, M., Koncsos, L., Rauch, W., Reichert, P., Shanahan, P., Vanrolleghem, P., 1998. River quality modelling: III. Future of the art. Water Science and Technology, 38 (11): 253-260. 


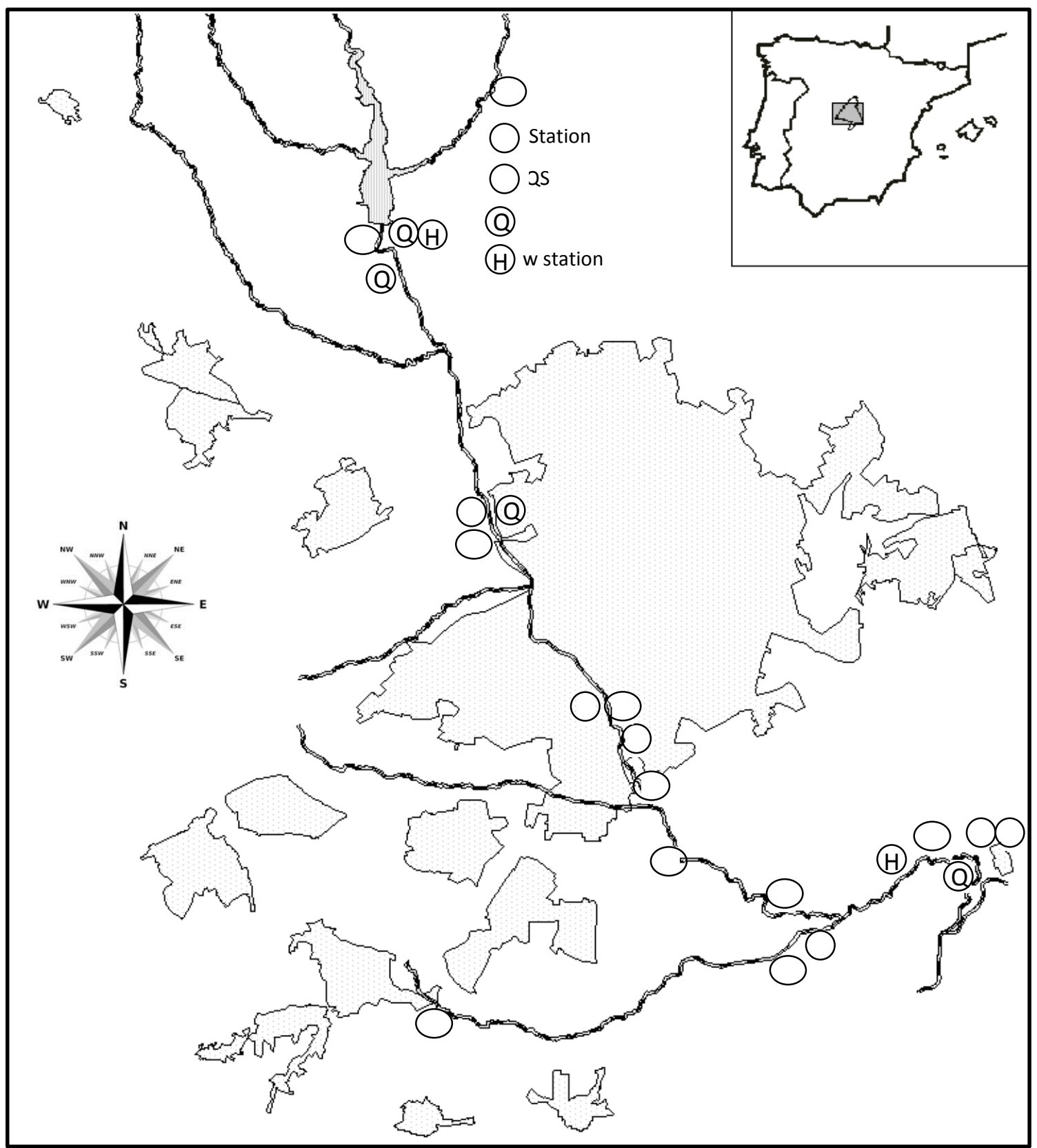

Figure 1. Manzanares River between El Pardo and El Rey Reservoirs (dotted area are urban districts).

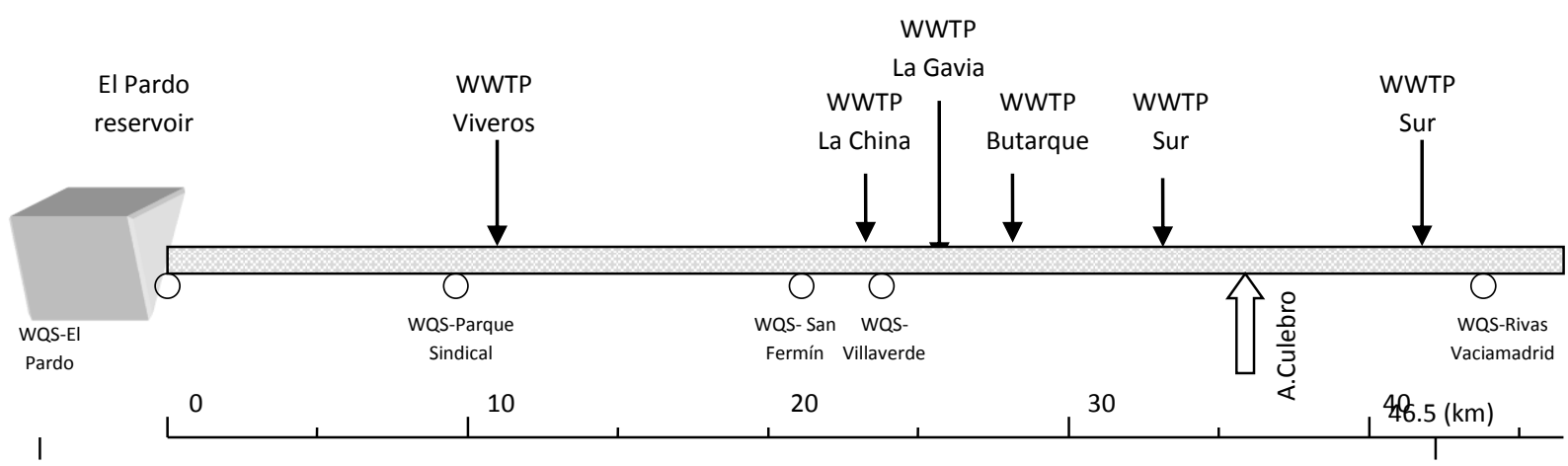

Figure 2. Schematic of discharges and measurement points 


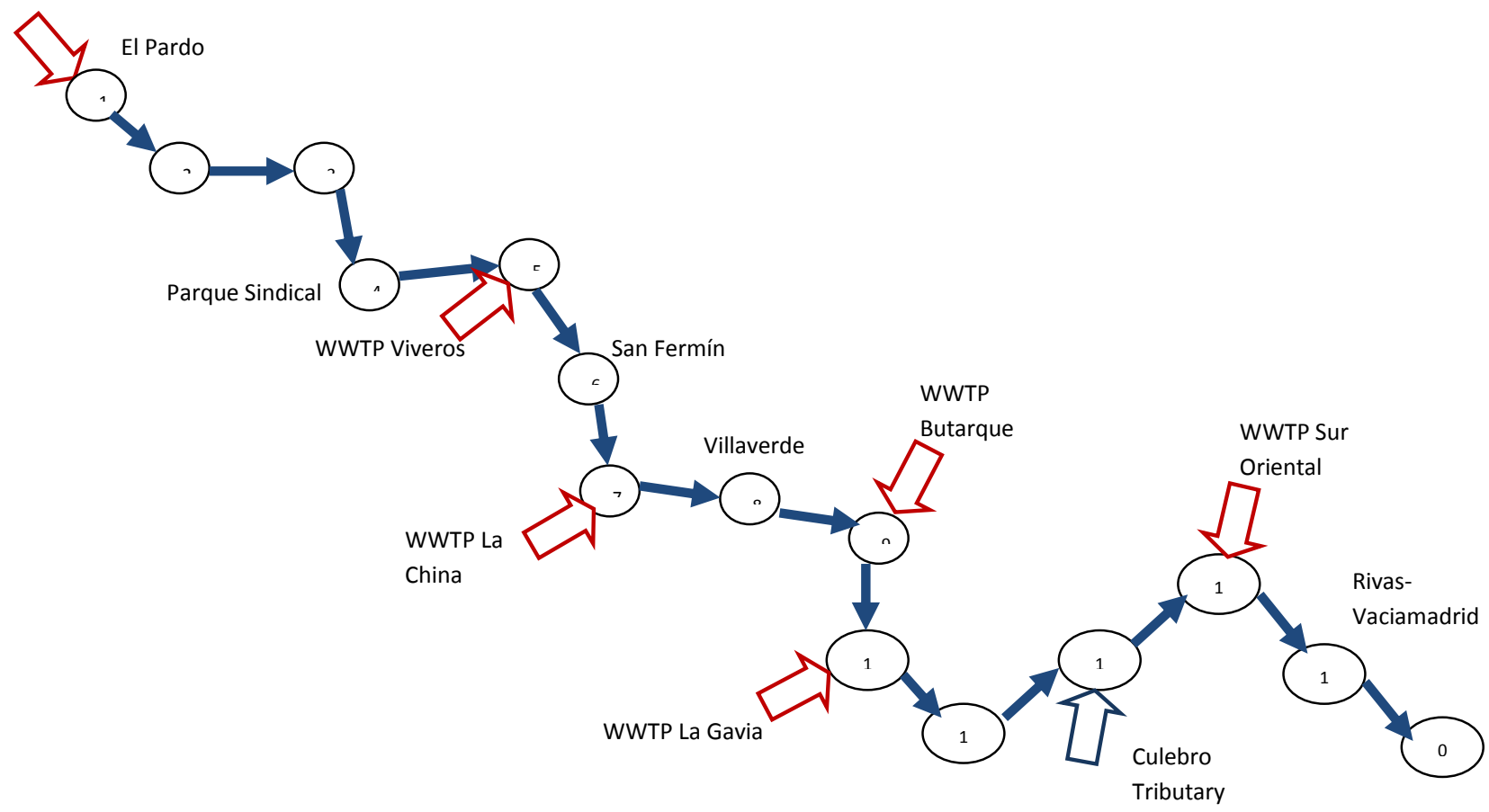

Figure 3. Network of the model

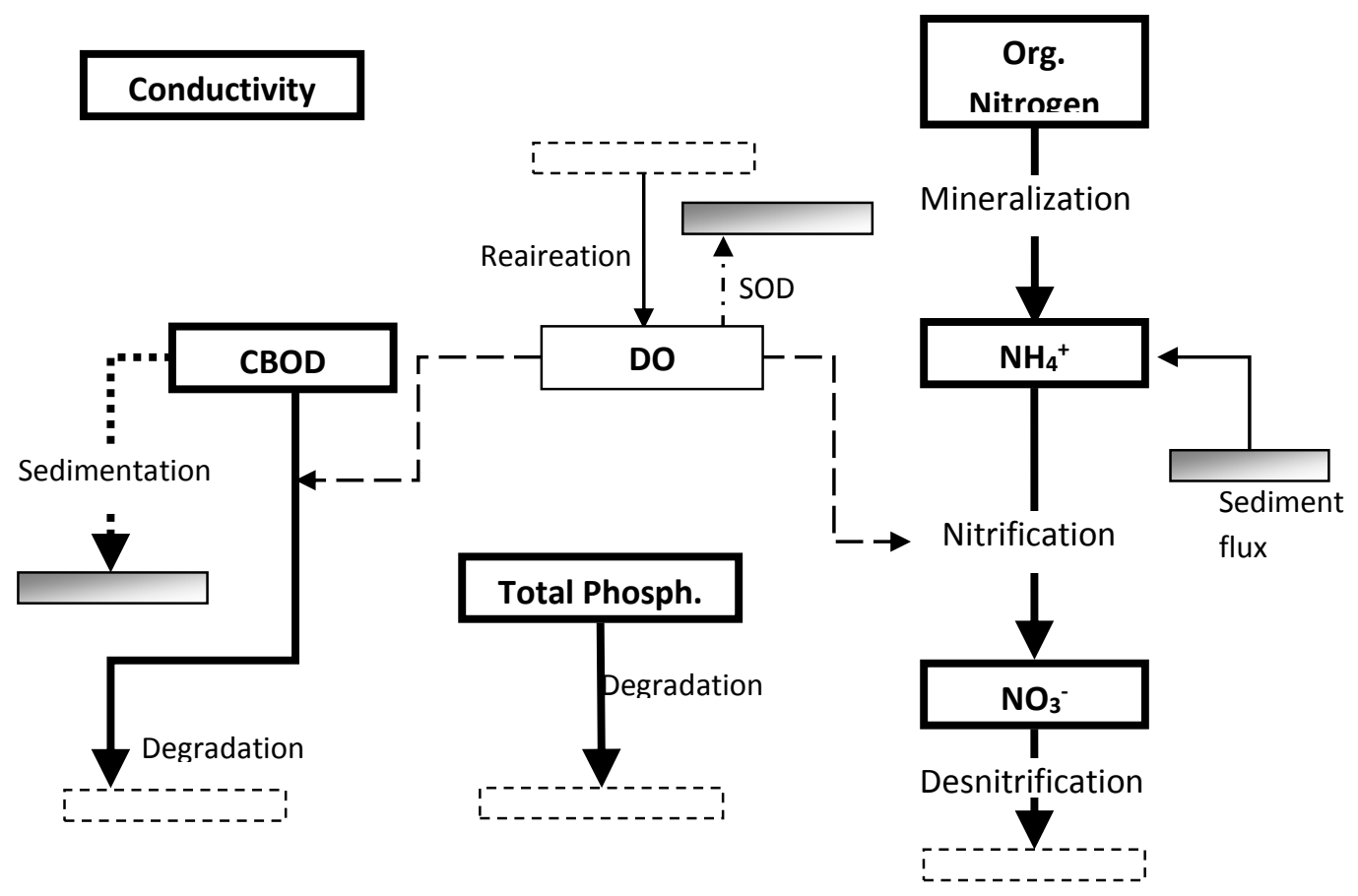

Figure 4. Processes considered in the model. 
CALIBRATION-VALIDATION 2001-2008
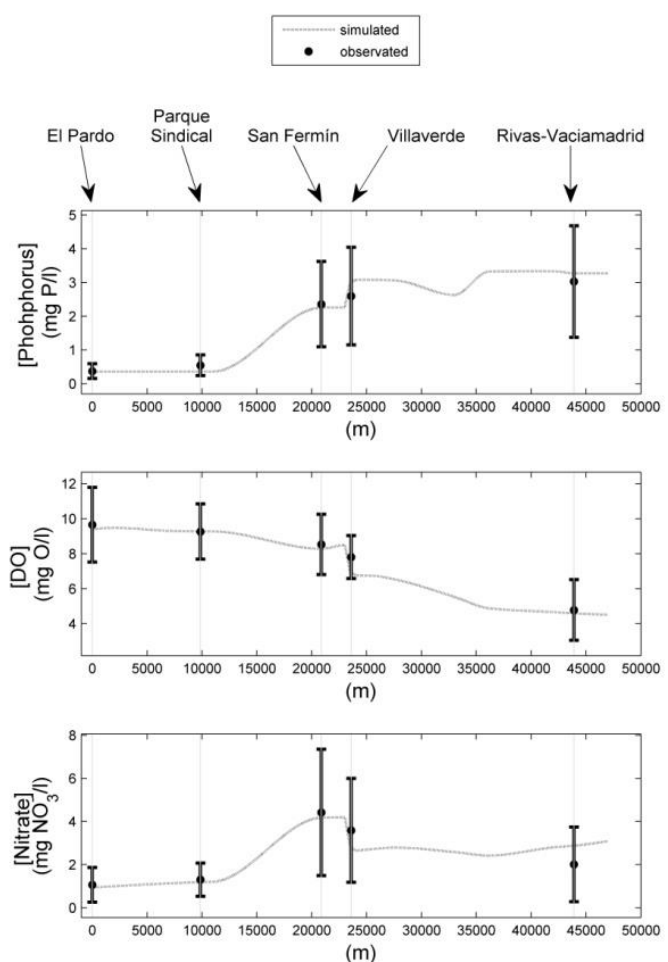
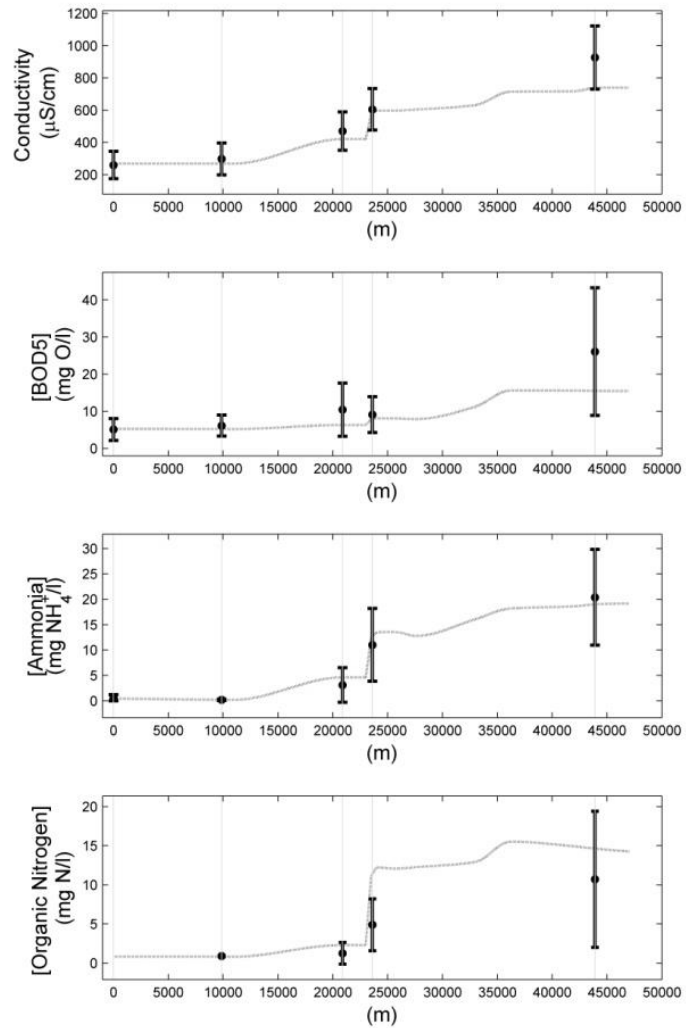

Figure 5-a. Average of simulated results and observed values for the calibration and validation periods.

STATION

Parque Sindical

$$
\begin{array}{|c|c|}
\hline \circ & \text { observated } \\
\hline & \text { simulated } \\
\hline
\end{array}
$$
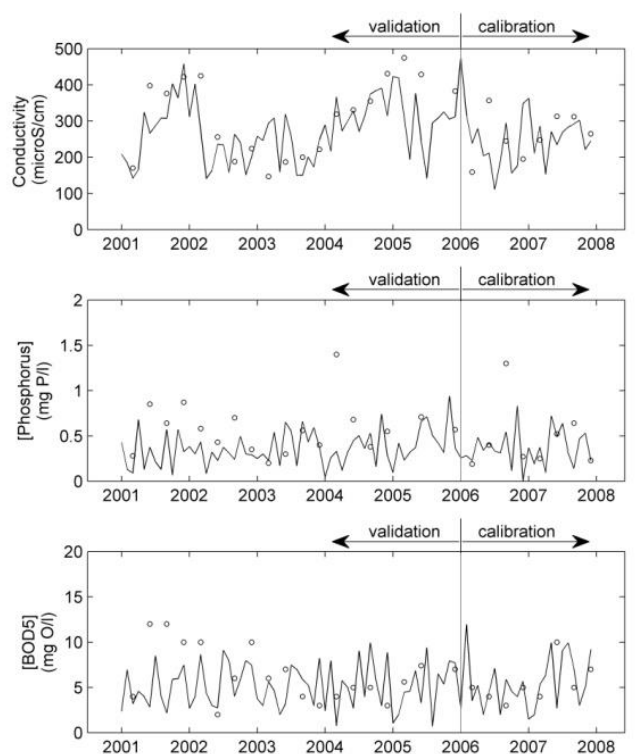
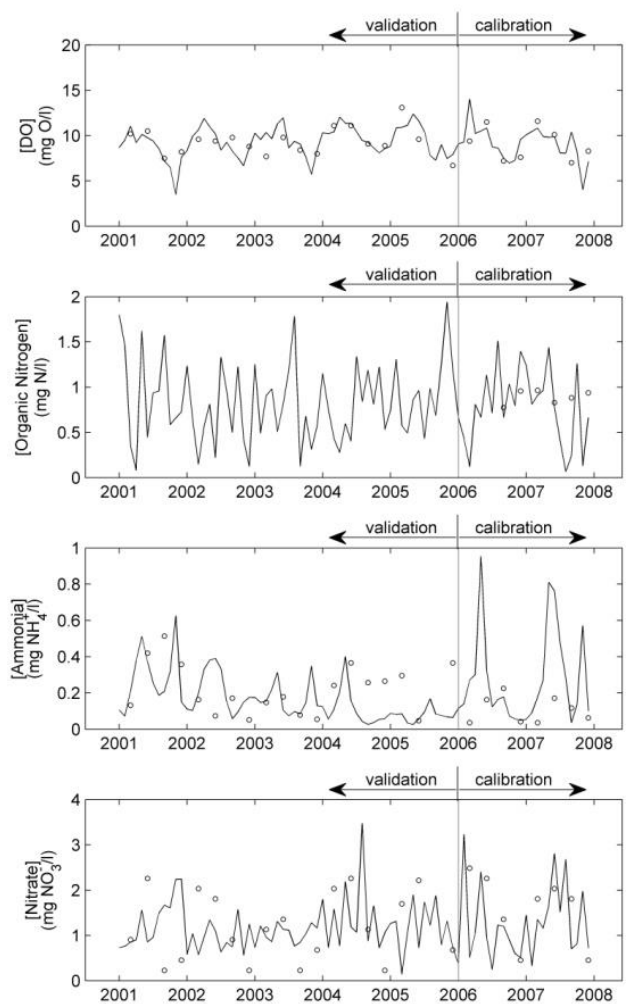
Figure 5-b. Time series of simulated results and observed values at Parque Sindical station.
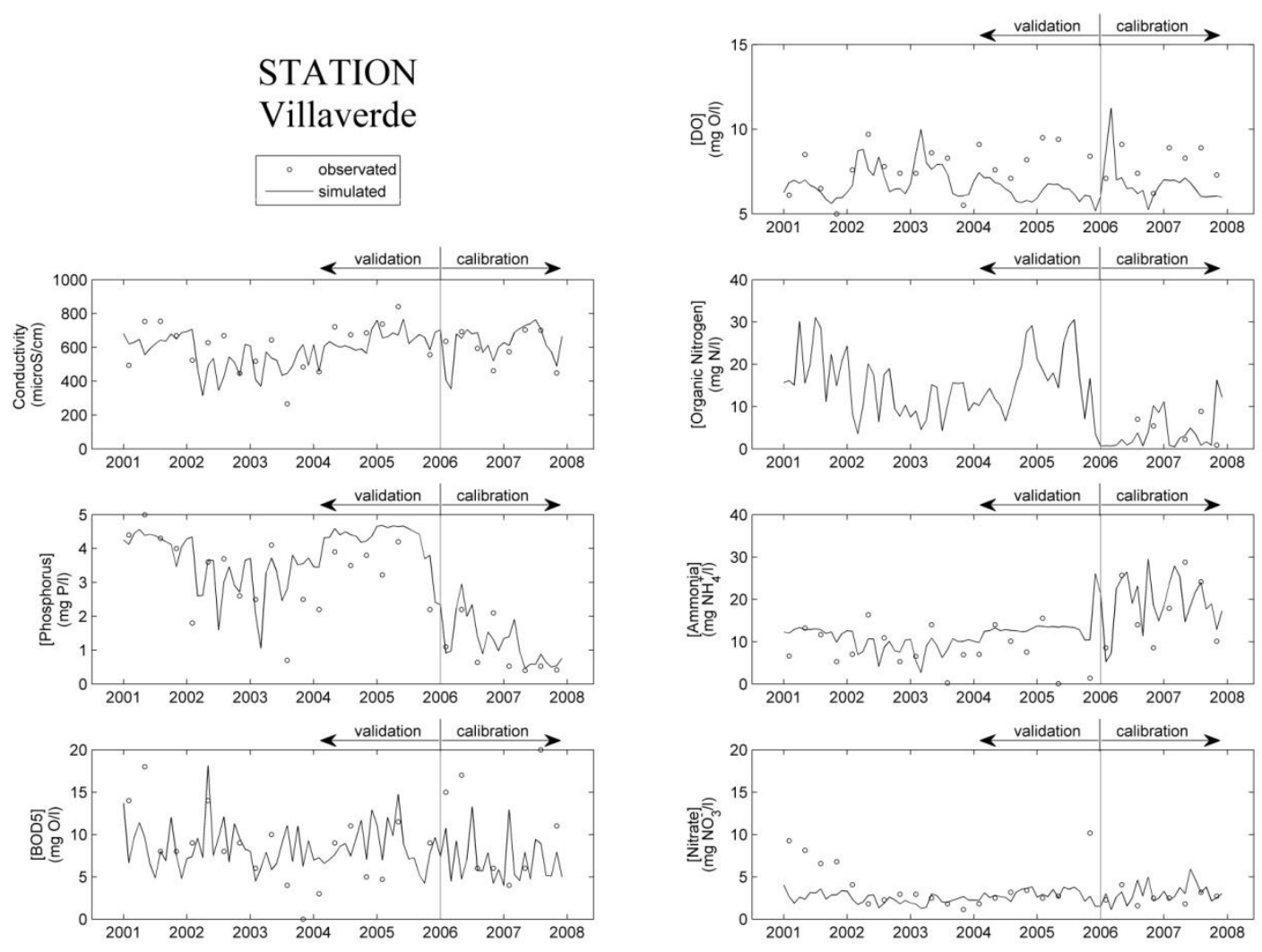

Figure 5-c. Time series of simulated results and observed values at Villaverde station 
STATION

San Fermín
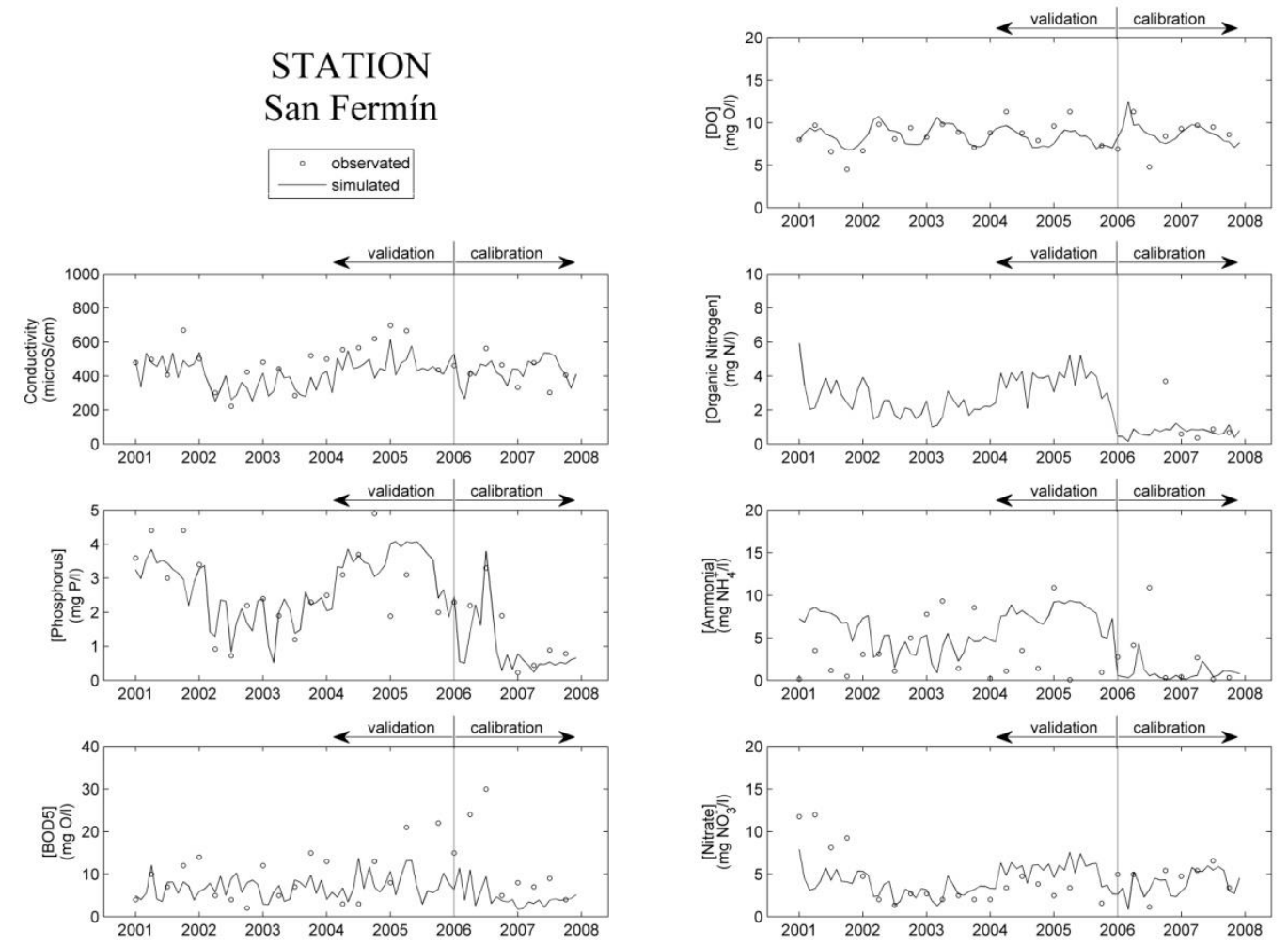

Figure 5-d. Time series of simulated results and observed values at San Fermín station. 

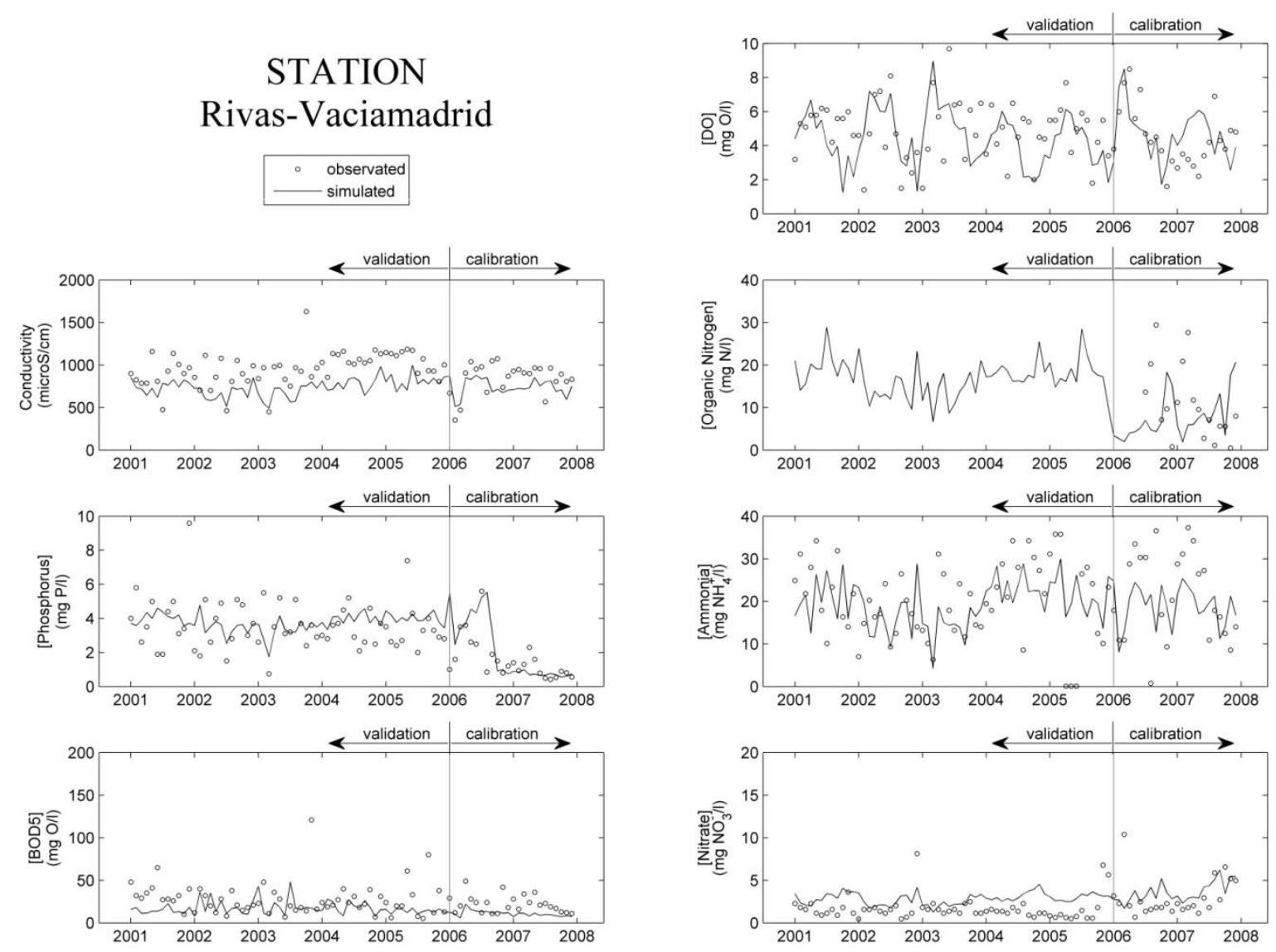

Figure 5-e. Time series of simulated results and observed values at Rivas-Vaciamadrid station.

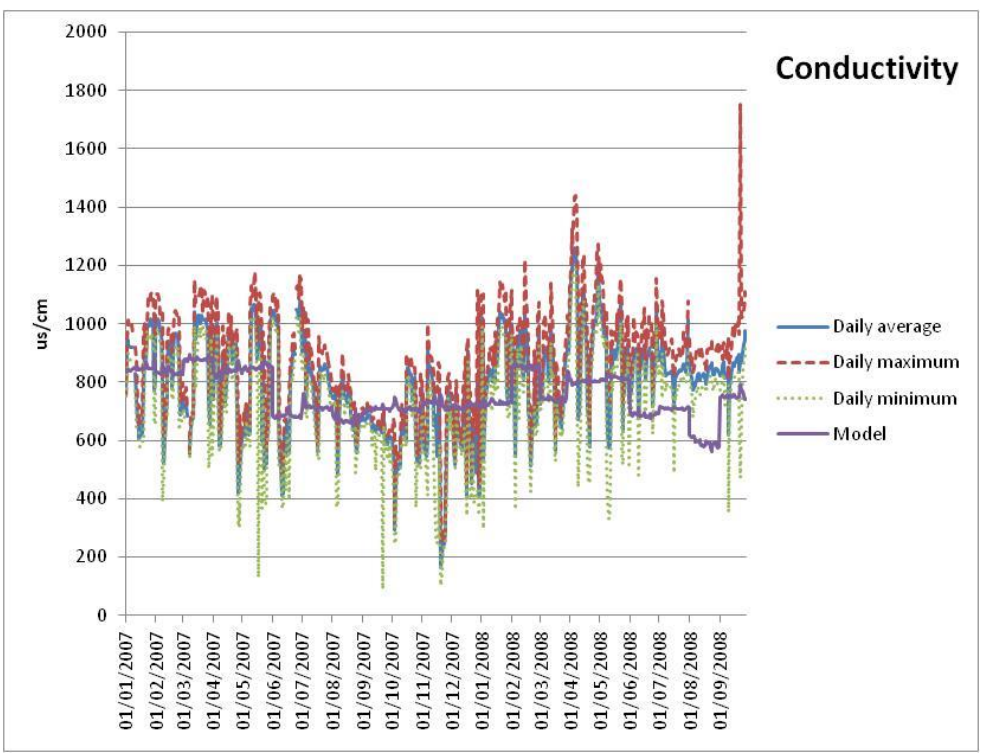

Fig 6 a. Observed and simulated (daily model) values. 


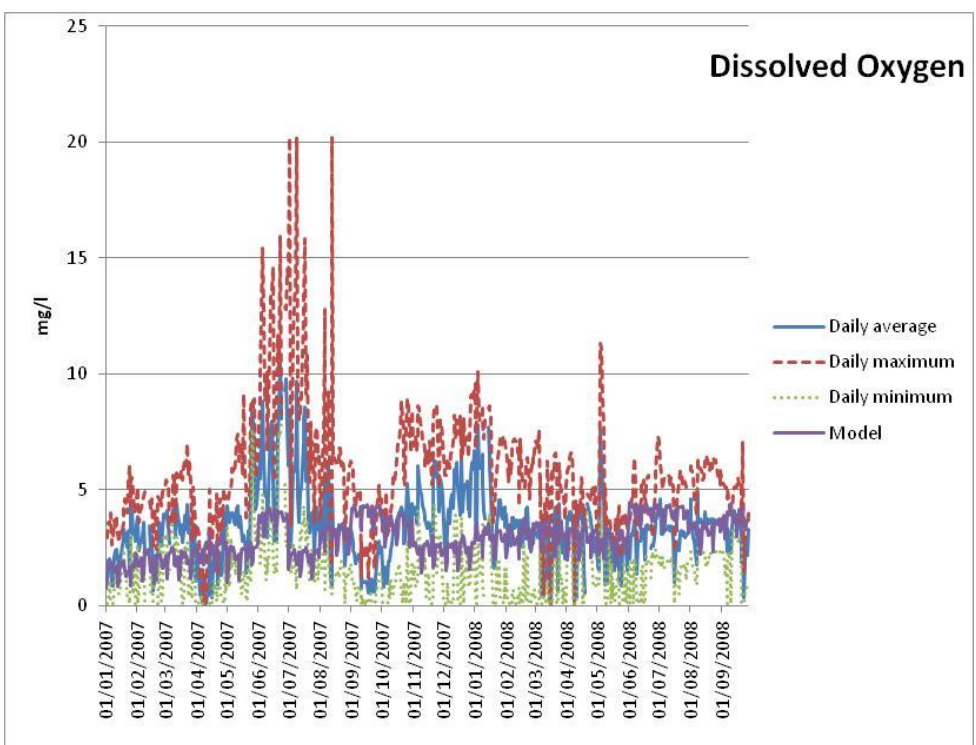

Fig 6 b. Observed and simulated (daily model) values.

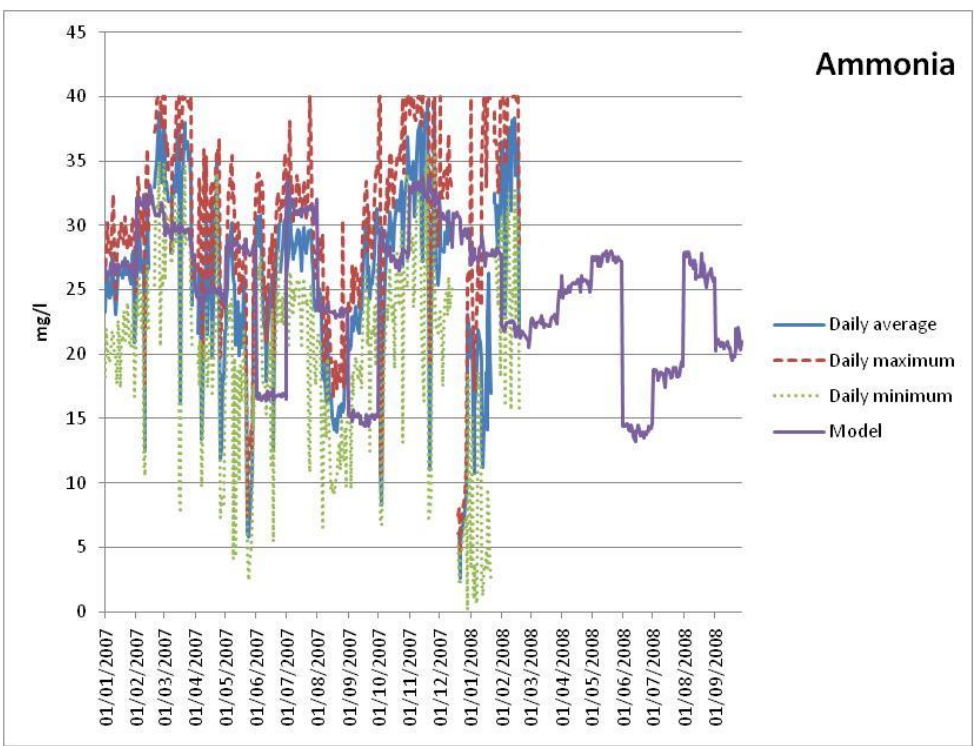

Fig 6 c. Observed and simulated (daily model) values. 
Simulation Results.

Nutrients Reduction

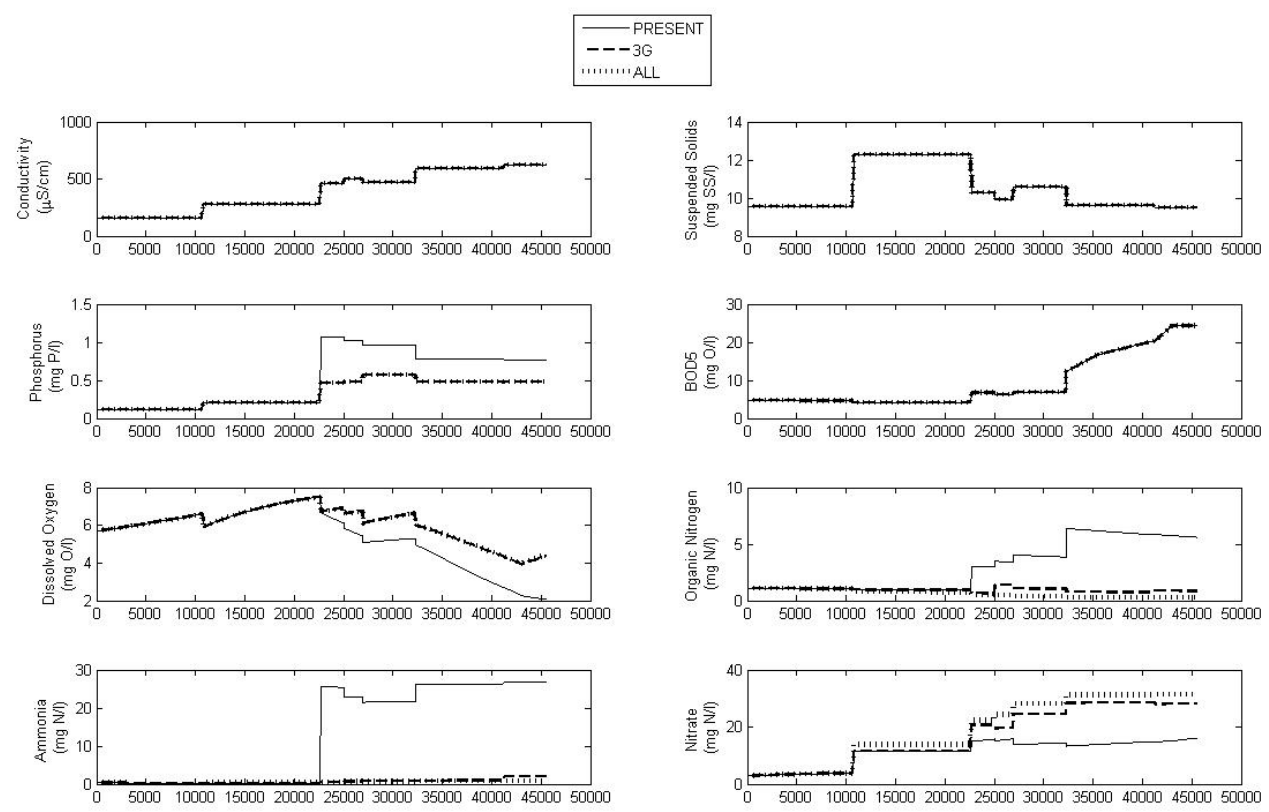

Figure 7 a. Simulation results. Nutrients reduction.

\section{Simulation Results. \\ Oxygen Augmentation}

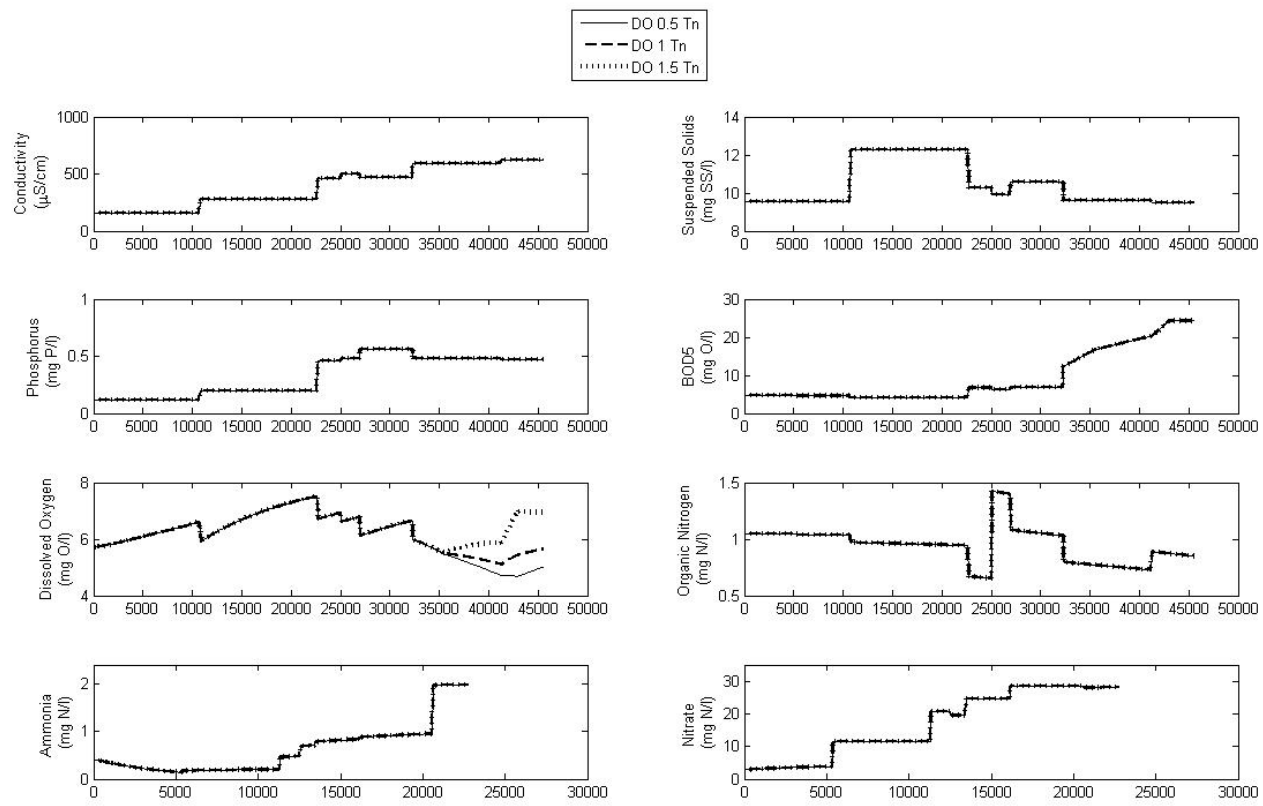

Figure 7 b. Simulation results. Oxygen augmentation. 
Simulation Results.

Flow Increment from El Pardo
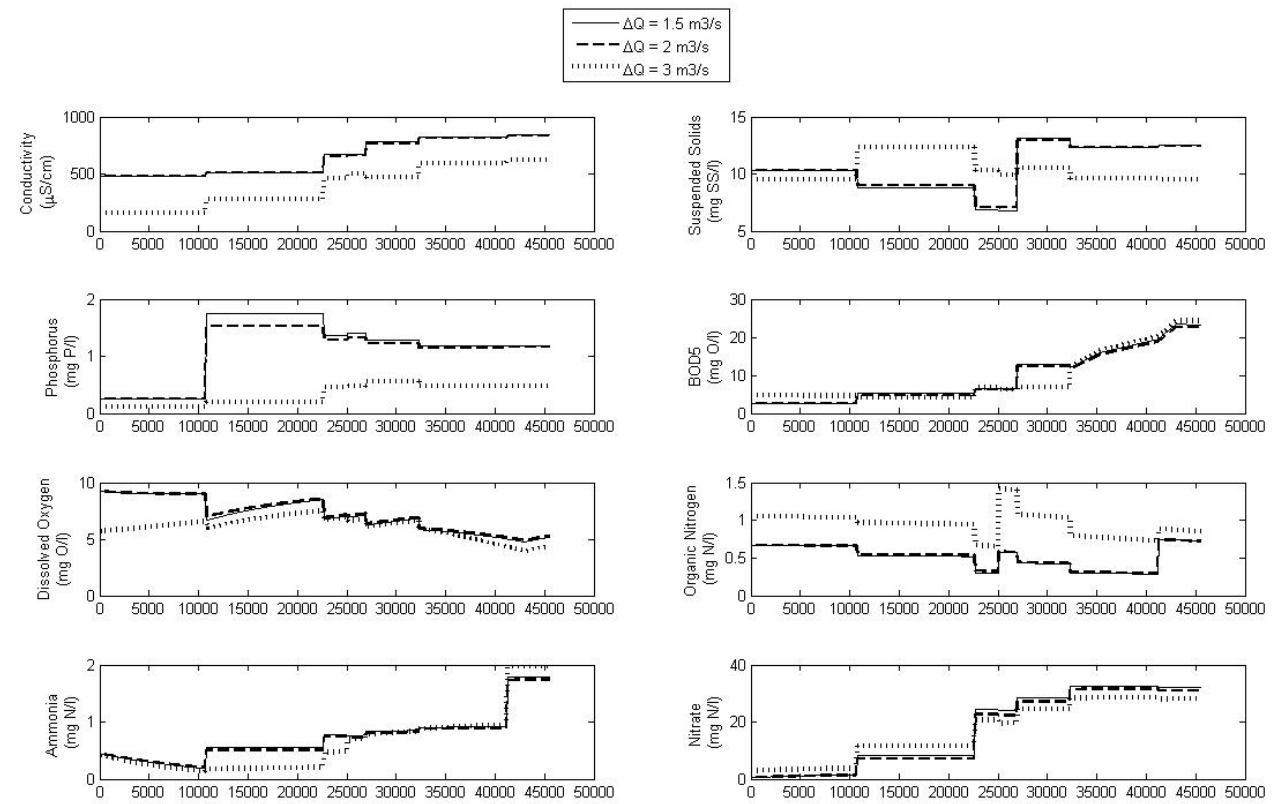

Figure 7 c. Simulation results. Increment river flow.
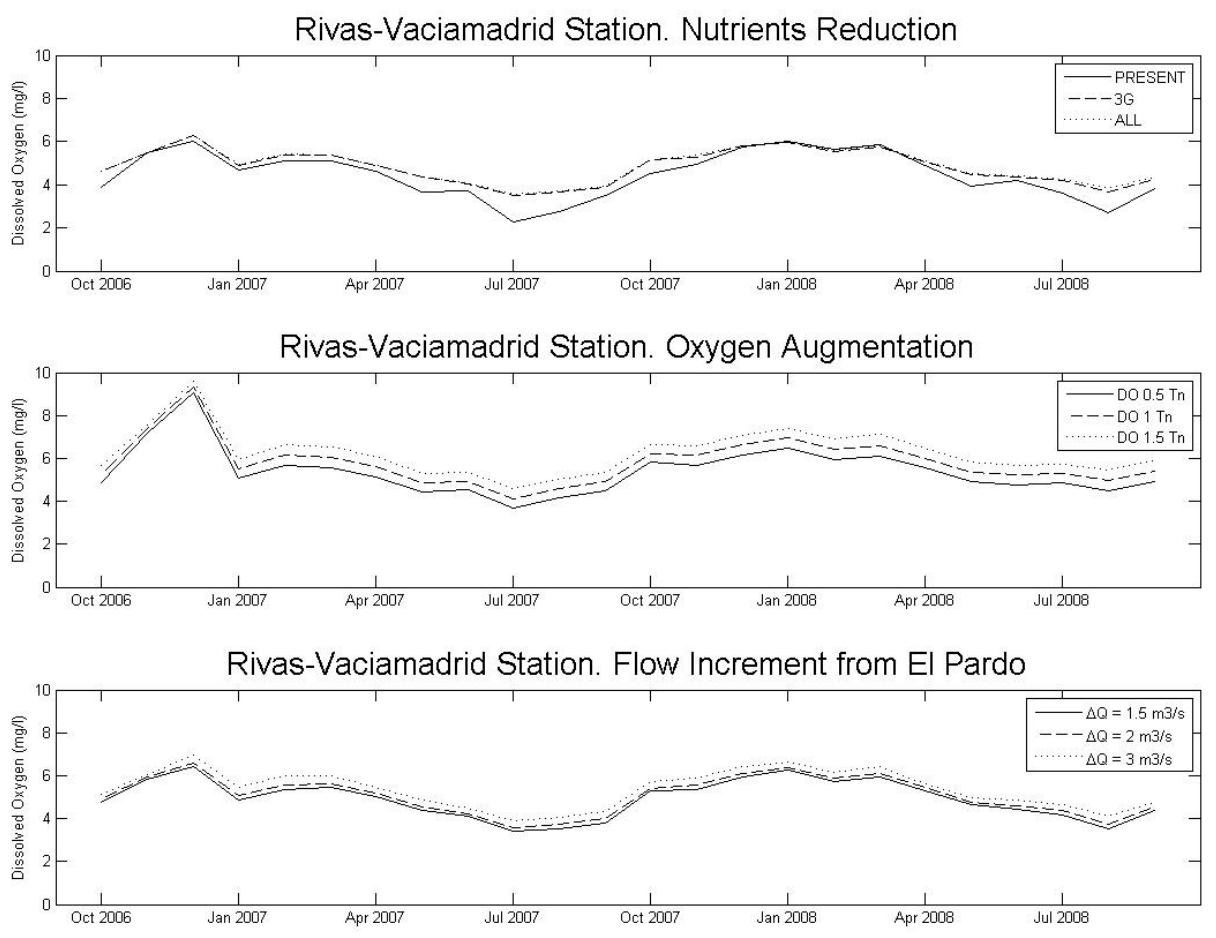

Figure $7 \mathrm{~d}$. Simulation results. Dissolved oxygen in Rivas for different scenarios. 


\begin{tabular}{|c|c|c|c|c|c|c|c|}
\hline $\begin{array}{l}\text { NTP \ } \\
\text { Constituent }\end{array}$ & IEROS & CHINA & GAVIA & TARQUE & $\mathbf{R}$ & R ORIENTAL & LEBRO ALTO \\
\hline Hab (*1000) & 29 & 75 & 0 & 00 & 00 & $\beta$ & 50 \\
\hline$w\left(m^{3} / s\right)$ & $\begin{array}{l}1.08 \\
0.1\end{array}$ & $\begin{array}{l}1.97 \\
0.1\end{array}$ & $\begin{array}{l}0.83 \\
0.09\end{array}$ & $\begin{array}{l}0.85 \\
0.15\end{array}$ & $\begin{array}{l}3.16 \\
0.46\end{array}$ & $\begin{array}{l}0.31 \\
0.03\end{array}$ & $\begin{array}{l}0.65 \\
0.11\end{array}$ \\
\hline nduct. $(\mu \mathrm{s} / \mathrm{cm})$ & $\begin{array}{l}588 \\
42\end{array}$ & $\begin{array}{l}857 \\
46\end{array}$ & $\begin{array}{l}785 \\
82\end{array}$ & $\begin{array}{l}594 \\
357\end{array}$ & $\begin{array}{l}883 \\
165\end{array}$ & $\begin{array}{l}1555 \\
142\end{array}$ & $\begin{array}{l}1014 \\
69\end{array}$ \\
\hline $\begin{array}{l}\text { sp. Solids } \\
g / I)\end{array}$ & $\begin{array}{l}5 \\
0.8\end{array}$ & $\begin{array}{l}6.2 \\
1.85\end{array}$ & $\begin{array}{l}9.6 \\
4.87\end{array}$ & $\begin{array}{l}16 \\
12.37\end{array}$ & $\begin{array}{l}8.35 \\
3.46\end{array}$ & $\begin{array}{l}8.15 \\
3.65\end{array}$ & $\begin{array}{l}18.73 \\
4.73\end{array}$ \\
\hline $\begin{array}{l}\text { t. Phosph. } \\
\text { g/l) }\end{array}$ & $\begin{array}{l}1.46 \\
1.72\end{array}$ & $\begin{array}{l}0.75 \\
0.34\end{array}$ & $\begin{array}{l}0.61 \\
0.23\end{array}$ & $\begin{array}{l}0.69 \\
0.33\end{array}$ & $\begin{array}{l}0.56 \\
0.19\end{array}$ & $\begin{array}{l}0.68 \\
0.42\end{array}$ & $\begin{array}{l}1.41 \\
0.37\end{array}$ \\
\hline $\begin{array}{l}\text { OD5 } \\
g / I)\end{array}$ & $\begin{array}{l}3.11 \\
1.59\end{array}$ & $\begin{array}{l}9.11 \\
6.05\end{array}$ & $\begin{array}{l}2.95 \\
0.98\end{array}$ & $\begin{array}{l}11.2 \\
2.96\end{array}$ & $\begin{array}{l}9.6 \\
1.96\end{array}$ & $\begin{array}{l}9.6 \\
2.12\end{array}$ & $\begin{array}{l}14.5 \\
4.87\end{array}$ \\
\hline $\begin{array}{l}\text { s. Oxygen } \\
g / I)\end{array}$ & 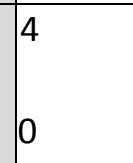 & 5 & $\begin{array}{l}4 \\
0\end{array}$ & $\begin{array}{l}4 \\
0\end{array}$ & $\begin{array}{l}4 \\
0\end{array}$ & $\begin{array}{l}4 \\
0\end{array}$ & $\begin{array}{l}4 \\
0\end{array}$ \\
\hline $\begin{array}{l}\text { g. Nitrogen } \\
\text { g/l) }\end{array}$ & $\begin{array}{l}0.75 \\
0.21\end{array}$ & $\begin{array}{l}9.6 \\
25.1\end{array}$ & $\begin{array}{l}11.54 \\
8.2\end{array}$ & $\begin{array}{l}5.69 \\
5.02\end{array}$ & $\begin{array}{l}14.42 \\
S=14.9\end{array}$ & $\begin{array}{l}16.76 \\
15.12\end{array}$ & $\begin{array}{l}27.39 \\
12.53\end{array}$ \\
\hline $\begin{array}{l}\text { gonnia } \\
\text { gNH4/I) }\end{array}$ & $\begin{array}{l}1.85 \\
2.29\end{array}$ & $\begin{array}{l}50.11 \\
10.9\end{array}$ & $\begin{array}{l}2.4 \\
5.03\end{array}$ & $\begin{array}{l}16.98 \\
11.05\end{array}$ & $\begin{array}{l}28.51 \\
13\end{array}$ & $\begin{array}{l}36.06 \\
10.75\end{array}$ & $\begin{array}{l}28.51 \\
13\end{array}$ \\
\hline $\begin{array}{l}\text { rates } \\
\text { gNO3/I) }\end{array}$ & $\begin{array}{l}27.23 \\
7.07\end{array}$ & $\begin{array}{l}9.35 \\
11.3\end{array}$ & $\begin{array}{l}11.9 \\
3.89\end{array}$ & $\begin{array}{l}9.9 \\
12.41\end{array}$ & $\begin{array}{l}10.2 \\
7.7\end{array}$ & $\begin{array}{l}10.2 \\
7.7\end{array}$ & $\begin{array}{l}10.2 \\
7.7\end{array}$ \\
\hline
\end{tabular}

Table 1. Main features of loads. X=mean; S=standard deviation. 


\begin{tabular}{|c|c|c|c|c|c|c|c|c|}
\hline Model reaches & $\begin{array}{c}\mathbf{K a} \\
\left(\mathbf{d}^{-1}\right)\end{array}$ & $\begin{array}{c}\text { SOD } \\
\left(\mathrm{gr} / \mathrm{m}^{2} \mathrm{~d}\right. \\
)\end{array}$ & $\begin{array}{c}\mathbf{K d} \\
\left(\mathbf{d}^{-1}\right)\end{array}$ & $\begin{array}{l}\text { Vsd } \\
(\mathbf{m} / \mathbf{d})\end{array}$ & $\begin{array}{c}\text { Knorg } \\
\left(d^{-1}\right)\end{array}$ & $\begin{array}{c}\text { VsNorg } \\
(\mathbf{m} / \mathbf{d})\end{array}$ & $\begin{array}{c}\text { Kn } \\
\left(d^{-1}\right)\end{array}$ & $\begin{array}{c}\text { Vs Phosp } \\
\text { (m/d) }\end{array}$ \\
\hline $\begin{array}{l}\text { Manz1: Downstream El } \\
\text { Pardo Reservoir }\end{array}$ & 3.15 & 0 & 0.001 & 0.02 & 0.001 & 0.02 & 5 & 0.001 \\
\hline Manz2: Majadahonda & 3.15 & 0 & 0.05 & 0.012 & 0.03 & 0.012 & 5 & 0.001 \\
\hline $\begin{array}{l}\text { Manz3: Majadahonda to } \\
\text { ParqueSindical }\end{array}$ & 3.15 & 0 & 0.05 & 0.012 & 0.03 & 0.012 & 5 & 0.001 \\
\hline $\begin{array}{l}\text { Manz4: ParqueSindical to } \\
\text { WWTP Viveros }\end{array}$ & 3.15 & 0 & 0.05 & 0.012 & 0.03 & 0.012 & 3 & 0.001 \\
\hline $\begin{array}{l}\text { Manz5: WWTP Viveros to } \\
\text { SanFermin }\end{array}$ & 4.55 & 0.1 & 0.05 & 0.015 & 0.1 & 0.015 & 0.1 & 0.015 \\
\hline $\begin{array}{l}\text { Manz6: SanFermin to } \\
\text { WWTP LaChina }\end{array}$ & 4.55 & 0.1 & 0.05 & 0.015 & 0.1 & 0.015 & 0.1 & 0.02 \\
\hline $\begin{array}{l}\text { Manz7: WWTP LaChina } \\
\text { to Villaverde }\end{array}$ & 4.55 & 0.12 & 0.06 & 0.018 & 0.5 & 0.018 & 0.2 & 0.02 \\
\hline $\begin{array}{l}\text { Manz8: Villaverde to } \\
\text { WWTP LaGavia }\end{array}$ & 3.57 & 0.12 & 0.06 & 0.018 & 0.5 & 0.018 & 0.2 & 0.02 \\
\hline $\begin{array}{l}\text { Manz9: WWTP LaGavia } \\
\text { to WWWTP Butarque }\end{array}$ & 3.57 & 0.15 & 0.075 & 0.018 & 0.5 & 0.018 & 0.25 & 0.042 \\
\hline $\begin{array}{l}\text { Manz10: WWTP Butarque } \\
\text { to WWTP Sur }\end{array}$ & 3.57 & 0.15 & 0.075 & 0.018 & 0.5 & 0.018 & 0.25 & 0.042 \\
\hline $\begin{array}{l}\text { Manz11: WWTP Sur to } \\
\text { Culebro }\end{array}$ & 3.57 & 0.18 & 0.075 & 0.018 & 0.5 & 0.018 & 0.25 & 0.042 \\
\hline $\begin{array}{l}\text { Manz12: Culebro to } \\
\text { WWTP SurOriental }\end{array}$ & 3.57 & 0.18 & 0.075 & 0.018 & 0.5 & 0.018 & 0.25 & 0.042 \\
\hline $\begin{array}{l}\text { Manz13: WWTP } \\
\text { SurOriental to } \\
\text { Vaciamadrid }\end{array}$ & 3.57 & 0.2 & 0.075 & 0.018 & 0.5 & 0.018 & 0.25 & 0.042 \\
\hline $\begin{array}{l}\text { Manz14: Vaciamadrid to } \\
\text { Rey Reservoir }\end{array}$ & 3.57 & 0.2 & 0.075 & 0.018 & 0.5 & 0.018 & 0.25 & 0.042 \\
\hline
\end{tabular}

Table 2. Calibrated parameters. Ka re-aeration; Kd CBOD degradation; Vsd sediment velocity of particulate CBOD; KNorg mineralizaion of organic nitrogen; Vsnorg sediment velocity of organic nitrogen; Kn nitrification of ammonia; Vs.Phosp velocity of sedimentation of particulate phosphorous. SOD sediment oxygen demand. 